\title{
30-Year Satellite Record Reveals Contrasting \\ Arctic and Antarctic Decadal Sea Ice Variability
}

\author{
D. J. Cavalieri and C. L. Parkinson \\ Laboratory for Hydrospheric Processes \\ NASA Goddard Space Flight Center \\ Greenbelt, MD 20771
}

\author{
K. Y. Vinnikov \\ Department of Meteorology \\ University of Maryland \\ College Park, MD 20742
}

\begin{abstract}
A 30-year satellite record of sea ice extents derived mostly from satellite microwave radiometer observations reveals that the Arctic sea ice extent decreased by $0.30 \pm 0.03 \times 10^{6} \mathrm{~km}^{2} / 10 \mathrm{yr}$ from 1972 through 2002 , but by $0.36 \pm 0.05 \times 10^{6} \mathrm{~km}^{2} / 10 \mathrm{yr}$ from 1979 through 2002 , indicating an acceleration of $20 \%$ in the rate of decrease. In contrast, the Antarctic sea ice extent decreased dramatically over the period 1973-1977, then gradually increased. Over the full 30-year period, the Antarctic ice extent decreased by $0.15 \pm 0.08 \times 10^{6} \mathrm{~km}^{2} / 10 \mathrm{yr}$. The trend reversal is attributed to a large positive anomaly in Antarctic sea ice extent in the early 1970's, an anomaly that apparently began in the late 1960 's, as observed in early visible and infrared satellite images.
\end{abstract}




\section{Introduction}

Polar sea ice has undergone marked changes during the last two decades (Bjørgo et al., 1997; Parkinson et al., 1999; Serreze et al., 2003; Stammerjohn and Smith, 1997; Zwally et al., 2002), with a noted asymmetry between Arctic and Antarctic variabilities and trends (Cavalieri et al., 1997). The Arctic sea ice extent decreased by $0.329 \pm 0.061 \times 10^{6} \mathrm{~km}^{2} / 10 \mathrm{yr}$ over the period 1979-1999 (Parkinson and Cavalieri, 2002), whereas the Antarctic sea ice extent increased by $0.112 \pm 0.042 \times 10^{6} \mathrm{~km}^{2} / 10 \mathrm{yr}$ for $1979-1998$ (Zwally et al., 2002). This hemispheric asymmetry is not inconsistent with some $\mathrm{GCM}$ simulations in which $\mathrm{CO}_{2}$ concentrations were increased gradually (Manabe et al., 1992; Cavalieri et al., 1997).

We have extended the analysis of Arctic and Antarctic sea ice variability from two to three decades (1973-2002) by bridging the gap between the Nimbus 7 data and the earlier Nimbus 5 satellite data record. The gap was bridged and the two satellite data records matched by using the National Ice Center (NIC) digital sea ice data set (Dedrick et al., 2001). Most of the recent satellite-based studies of sea ice variability have concentrated on the period since late 1978 , when the Nimbus 7 satellite was launched.

\section{Sources of Data, Data Processing, and Matching Time Series}

The data sets used in compiling the three decade sea ice record include those from the Nimbus 5 Electrically Scanning Microwave Radiometer (ESMR) (December 1972 - March 1977), the NIC (January 1972 - December 1994 for the Arctic, January 1973 - December 1994 for the Antarctic), and the combined Nimbus 7 Scanning Multichannel Microwave Radiometer (SMMR)/ Defense Meteorological Satellite Program (DMSP) Special Sensor Microwave Imager (SSMI) (October 1978 - December 2002). Previously, ice extents from the SMMR and three SSMI sensors were matched to provide a nearly continuous data set for 1978-1996 (Cavalieri et al., 1999). We have extended this time series through 2002 by using more recent SSMI data. 
The NIC ice extent data are used in this study to bridge the gap between the ESMR and SMMR/SSMI data. The need for matching satellite data records arises from differences in sensor operating frequency, incidence angle, footprint size, and local observation time. This necessitates either a period of overlap between the two sensors or a data record that bridges the gap and provides overlap with each of the separate data records.

The daily ESMR brightness temperature data were mapped to the same polar stereographic grid used for the SMMR/SSMI 24-year (1979-2002) data set, then re-calibrated, cleaned by deleting bad data, and spatially interpolated for missing pixels. The brightness temperature maps were converted to sea ice concentration maps using a simple linear algorithm similar to the single-channel ESMR algorithms (Parkinson et al., 1987; Zwally et al., 1983a), with revised algorithm coefficents. As was done earlier for the SMMR/SSMI combined data set (Cavalieri et al., 1999), the ice concentration maps were then subjected to a land spillover correction and SST filter to minimize weather contamination over open ocean areas before temporally interpolating for days of missing data. A 7-day moving average was applied to the ESMR ice concentration maps to reduce weather effects at the ice edge. Seven days is much shorter than the time scale of temporal autocorrelation of ice extents, which has been estimated to be about 50 days in both hemispheres (Walsh and Johnson, 1979; Vinnikov et al., 2002). Finally, sea ice extents were calculated by summing the areas of all pixels with ice concentrations of at least $20 \%$. The $20 \%$ cutoff, in contrast to the usual $15 \%$, was used to eliminate additional spurious weather effects at the ice edge. The use of two ice-edge definitions (based on $20 \%$ for the ESMR data and $15 \%$ for the remaining ice extents) is resolved in the process of matching the different sea ice extent time series. Furthermore, Parkinson et al. (1999) show that sea ice trends are relatively insensitive to the choice of ice concentration cutoff over the range $15 \%-30 \%$. Neither the 7-day moving 
average nor the increase to a $20 \%$ cutoff, for further weather clearing, was required for the SMMR/SSMI time series, because the SMMR and SSMI weather filters are based on the multichannel microwave data.

Weekly Northern Hemisphere (NH) sea ice concentration files obtained from the NIC (Dedrick et al., 2001) were mapped to the SSMI polar grid, and weekly ice extents were calculated by summing all pixels with ice concentrations of at least $15 \%$. Because the updated weekly Southern Hemisphere ( $\mathrm{SH})$ ice concentration maps were not available from the NIC, we used the NIC weekly SH sea ice extent time series (Ropelewski, 1983), available from the NIC web site (http://www.natice.noaa.gov/PUB/Archive/antarctic/). The weekly NIC ice extents, which were interpreted as daily ice extents dated two days before the date of the ice chart's release, are used only as a means to bridge the gap between the two satellite data records. We did this to minimize the effect of inherent uncertainties in the NIC record (Dedrick et al., 2001), including uncertainties resulting from nonuniform and different sources of data, and the subjective determination of sea ice extent by analysts. During the early part of the NIC record, significant areas of data represent interpolations or perceived climatological conditions, whereas in the late 1970's, ESMR and SMMR data were used by analysts to "calibrate" their estimates of ice concentration (Dedrick et al., 2001). For these reasons, we opted to maximize the use of the passive microwave satellite data and use the NIC data only to fill gaps in the satellite data record.

The ESMR and SMMR/SSMI time series were matched by first defining two overlap periods: a 5.0-year period for NIC-SMMR (Day 305, 1978 through Day 305, 1983) and a 4.3year period for NIC-ESMR (Day 342, 1972 through Day 77, 1977). We used the difference between average seasonal cycles for the NIC-SMMR overlap period to estimate the seasonal bias of the NIC data relative to the SMMR/SSMI data. We adjusted the NIC seasonal cycle by 
adding the SMMR/SSMI-NIC average seasonal cycle bias on a day-by-day basis, while retaining the NIC anomalies. Next, we similarly used the NIC-ESMR overlap period to adjust the ESMR data to the adjusted NIC data. We then compiled a time series of observed daily extents using the adjusted NIC data for 1972 in the Arctic and to fill gaps between ESMR and SMMR data in both hemispheres.

\section{Results}

The results were obtained using a statistical technique that is based on linear regression, but with periodic basis functions instead of constant coefficients (Vinnikov et al., 2002). These functions approximate seasonal variations of multi-year averages and of a linear trend parameter for the period of observation. The first four Fourier harmonics of the annual cycle have been used to approximate these variations in sea ice extents. This approach provides climate statistics without having to assume stationarity of the time series. The application of this technique to the 30-year sea ice extent record provides us with the expected value, anomalies, and trends on a daily basis. From these we also calculate monthly and annual trends.

The largest variability for both hemispheres is the seasonal cycle (Figure 1). In the Arctic the trend line shows an overall decrease in sea ice extent during the 31 -year period. This is particularly evident during the summer months (Figure 1a), as was the case for the 21-year record (Parkinson and Cavalieri, 2002). The ten lowest September ice extents occurred since 1989, with the lowest occurring most recently in 2002 (Serreze et al., 2003). The daily anomalies (Figure 1a) range from $-1.5 \times 10^{6} \mathrm{~km}^{2}$ in 1995 to $1.0 \times 10^{6} \mathrm{~km}^{2}$ in 1996. The reason these extreme anomalies occur in successive years is uncertain, but may be related to the large interannual variability in the number of Arctic cyclones (e.g., Maslanik et al., 1996). The 365- 
day running mean of the daily anomalies suggests a dominant interannual variability of about 5 years (Figure 1a).

Monthly and annual trends for both the Arctic (1972-2002) and Antarctic (1973-2002) are summarized in Table 1, which also includes trends for the SMMR/SSMI period (1979-2002). For the Arctic, all months have negative trends and the magnitude of the trend is greater in September, the month of minimum ice extent, than in March, the month of ice maximum. This results in an increase in the average amplitude of the 6-month seasonal variation of about $0.3 \mathrm{x}$ $10^{6} \mathrm{~km}^{2}$ over the 31-year period; this is less than the $0.5 \times 10^{6} \mathrm{~km}^{2}$ reported earlier for the period 1979-1999 (Vinnikov et al., 2002). The trend magnitudes for the 31-year period range from a maximum of $0.38 \times 10^{6} \mathrm{~km}^{2} / 10 \mathrm{yr}$ in September to a minimum of $0.20 \times 10^{6} \mathrm{~km}^{2} / 10 \mathrm{yr}$ in February. The trend line for the 31-year Arctic period (1972-2002) has a slope of $-0.30 \pm 0.03 \mathrm{x}$ $10^{6} \mathrm{~km}^{2} / 10 \mathrm{yr}$, while that for $1979-2002$ has a slope of $-0.36 \pm 0.05 \times 10^{6} \mathrm{~km}^{2} / 10 \mathrm{yr}$, indicating a $20 \%$ greater trend for the 24 -year period. The slope for the 24 -year period is close to the $-0.33 \pm$ $0.06 \times 10^{6} \mathrm{~km}^{2} / 10 \mathrm{yr}$ value reported by Parkinson and Cavalieri (2002) for 1979-1999 and to the $-0.32 \pm 0.04 \times 10^{6} \mathrm{~km}^{2} / 10 \mathrm{yr}$ value reported by Bjørgo et al. (1997) for 1978-1995.

For the SH, the linear trend for the 30 -year period is $-0.15 \pm 0.08 \times 10^{6} \mathrm{~km}^{2} / 10 \mathrm{yr}$, in sharp contrast with the positive trend of $0.11 \pm 0.04 \times 10^{6} \mathrm{~km}^{2} / 10 \mathrm{yr}$ obtained by Zwally et al. (2002) for the 20-year period 1979-1998. The addition of the years 1973-1975 creates the overall negative trend. From 1973 through 1977 the annual mean ice cover decreased by almost $2 \times 10^{6} \mathrm{~km}^{2}$ (Figure 1b). From 1977 through 2002 there is a gradual recovery at the rate of $0.10 \pm 0.05 \times 10^{6}$ $\mathrm{km}^{2} / 10 \mathrm{yr}$. 
The SH trends by month (Table 1) have also changed significantly, with the highest magnitude trend $\left(-0.36 \pm 0.11 \times 10^{6} \mathrm{~km}^{2} / 10 \mathrm{yr}\right)$ for the 30-year period occurring in January (summer) and all trends for the 30-year period showing negative signs, as in the Arctic. In contrast, most trends for the last 24 years were positive, with the maximum trend $\left(0.28 \pm 0.15 \times 10^{6} \mathrm{~km}^{2} / 10 \mathrm{yr}\right)$ occurring in May (autumn).

\section{Conclusions}

Daily, monthly, and annual trends for three decades of Arctic and Antarctic sea ice extents have been generated utilizing a statistical technique that does not assume stationarity of the time series (Vinnikov et al., 2002). The resulting sea ice extent anomalies resemble anomalies for the period 1973-2000 published previously for the Antarctic (see Figure 2.16 in IPCC (2001)), but differ substantially from those published for the Arctic (see Figure 2.14 in IPCC (2001)), although both show negative overall trends. The reason for the Arctic differences during the early part of the period 1973-2000 is apparently the result of the IPCC (2001) study using different historical data sets in combination with the more current satellite sea ice data records. Additionally, there may have been differences in the method of data set blending, but this was not explained or referenced in IPCC (2001). The time series presented in this paper are considered to be more consistent, because our primary source of data is satellite observations, using the blended ice extent data from NIC only to match the satellite time series and to fill gaps in the satellite records.

The NH anomalies show a predominant period of 5 years, similar to what was reported by Cavalieri et al. (1997) for 1978-1996. This 5-year period falls within the broad spectral peak centered at 4.2 years obtained from an analysis of sea ice extent, area, and the Length of Day (LOD) index, used as a proxy for the El Nino/Southern Oscillation.(ENSO) (Gloersen, 1995). 
Regional Arctic sea ice variations result from atmospheric circulation changes and in particular from ENSO and North Atlantic Oscillation (NAO) events (Deser et al., 2000; Maslanik et al., 1996; Mysak et al., 1996; Parkinson, 2000). Patterns of Arctic surface air temperature changes and trends (Rigor et al., 2000) are consistent with regional changes in sea ice extent (Deser et al., 2000). A dominant mode of Arctic variability is the Arctic Oscillation (AO), and its strong positive phase during the 1990s may account for much of the recent decrease in Arctic ice extent. The AO explains more than half of the surface air temperature trends over much of the Arctic (Rigor et al., 2000).

In contrast to the $\mathrm{NH}$, the SH sea ice cover decreased dramatically over the period 19731977 , then increased at an overall rate of $0.10 \pm 0.05 \times 10^{6} \mathrm{~km}^{2} / 10 \mathrm{yr}$ from 1977 through 2002. This trend reversal results from the large positive anomaly in Antarctic sea ice extent observed in the early 1970's (Figure 1b). The decreasing positive anomaly from 1973 to 1976 (Figure 1b) is part of a longer period sea ice anomaly that began in the late 1960's and was observed in early visible and infrared satellite images (Streten, 1973; Sissala et al., 1972; Zwally et al., 1983b). From 1968 to 1973 there was an increase in ice extent, preceding the 1973 - 1976 decrease (see Figure 5 in Zwally et al. (1983b)). The large positive sea ice extent anomaly in 1973 has been associated with a "cold" ENSO event (Streten, 1973; Carleton, 1989). The fact that this short-term positive anomaly results in a negative trend for the 30-year period emphasizes the need for a longer time series extended back in time using, for instance, available visible and infrared satellite measurements.

In addition to ENSO events, longer term atmospheric variations have been identified including appreciable changes in SH tropospheric circulation at middle and high latitudes since the 1970s (Hurrell and Van Loon, 1994). These changes are also evident in the trend 
toward more positive SH annual mode indices over the last few decades (Thompson and Wallace, 2000), with the transition from mostly negative to mostly positive indices occurring during the 1970s. The more positive indices are associated with stronger westerlies and cooler temperatures over much of Antarctica (Thompson and Solomon, 2002). Exactly how this trend is related, if at all, to the increase in sea ice extent since the 1970's remains to be determined.

\section{Acknowledgments}

We thank K. Dedrick of the National Ice Center for providing the sea ice data sets and for his valuable assistance. The National Snow and Ice Data Center provided the DMSP SSM/I radiances. This work was supported by NASA's Cryospheric Sciences Research Program. KYV was also supported by NOAA grant NA06GP0403.

\section{References}

Bjørgo, E., O. M. Johanessen, and M. W. Miles, Analysis of merged SMMR-SSMI time series of Arctic and Antarctic sea ice parameters 1978-1995, Geophys. Res. Lett. 24, 413-416, 1997.

Carleton, A. M., Antarctic sea-ice relationships with indices of the atmospheric circulation of the southern hemisphere, Climate Dynamics, 3, 207-220, 1989.

Cavalieri, D. J., P. Gloersen, C. L. Parkinson, J. C. Comiso, and H. J. Zwally, Observed hemispheric asymnmetry in global sea ice changes, Science, 272, 1104-1106, 1997.

Cavalieri, D. J., C. L. Parkinson, P. Gloersen, J. C. Comiso, and H. J. Zwally, Deriving longterm time series of sea ice cover from satellite passive-microwave multisensor data sets, $J$. Geophys. Res., 104, 15803-15814, 1999. 
Dedrick, K. R., K. Partington, M. Van Woert, C. A. Bertoia, and D. Benner, U.S. National/Navy Ice Center digital sea ice data and climatology, Canadian Journal of Remote Sensing, 27, 457$475,2001$.

Deser, C., J. E. Walsh, and M. S. Timlin, Arctic sea ice variability in the context of recent atmospheric circulation trends, J. Climate, 13, 617-633, 2000.

Gloersen, P., Modulations of hemispheric sea-ice cover by ENSO events, Nature, 373, 503$506,1995$.

Hurrell, J. W., and H. Van Loon, A modulation of the atmospheric annual cycle in the southern hemisphere, Tellus, 46A, 325-338, 1994.

IPCC: Climate Change 2001: The Scientific Basis. Contribution of Working Group I to the Third Assessment Report of the Intergovernmental Panel on Climate Change. [J. T. Houghton, Y. Ding, D. J. Griggs, M. Noguer, P. J. van der Linden, X. Dai, K. Maskell, C. Johnson (eds.)], Cambridge University Press, Cambridge, 881 pp., 2001.

Manabe, S., M. J. Spelman, and R. J. Stouffer, Transient responses of a coupled oceanatmosphere model to gradual changes of atmospheric CO2. Part II: Seasonal response, $J$. Climate, 5, 105-126, 1992.

Maslanik, J. A., M. C. Serreze, and R. G. Barry, Recent decreases in Arctic summer ice cover and linkages to atmospheric circulation anomalies, Geophys. Res. Lett., 23, 1677-1680, 1996. Mysak, L. A., R. G. Ingram, J. Wang, and A. van der Baaren, The anomalous sea-ice extent in Hudson Bay, Baffin Bay and the Labrador Sea during three simultaneous NAO and ENSO episodes, Atmosphere-Ocean, 34, 313-343, 1996.

Parkinson, C. L., Recent trend reversals in Arctic sea ice extents: Possible connections to the North Atlantic Oscillation, Polar Geography, 24, 1-12, 2000. 
Parkinson, C. L., and D. J. Cavalieri, A 21-year record of Arctic sea-ice extents and their regional, seasonal and monthly variability and trends, Annals of Glaciol., 34, 441-446, 2002. Parkinson, C. L., D. J. Cavalieri, P. Gloersen, H. J. Zwally, and J. C. Comiso, Arctic sea ice extents, areas, and trends, 1978-1996, J. Geophys. Res., 104, 20837-20856, 1999.

Parkinson, C. L., J. C. Comiso, H. J. Zwally, D. J. Cavalieri, P. Gloersen, and W. J. Campbell, Arctic Sea Ice, 1973-1976: Satellite Passive-Microwave Observations, NASA, SP-489, Washington, DC, 1987.

Rigor, I. G., R. L. Colony, and S. Martin, Variations in air surface temperature observations in the Arctic, 1979-97, J. Climate, 13, 896-914, 2000.

Ropelewski, C. F., Spatial and temporal variations in Antarctic sea ice (1973-82), J. Climate and Applied Meteor., 22, 470-473, 1983.

Serreze, M. C., J. A. Maslanik, T. A. Scambos, F. Fetterer, J. Stroeve, K. Knowles, C. Fowler, S. Drobot, R. G. Barry, and T. M. Haran, A record minimum Arctic sea ice extent and area in 2002, Geophys. Res. Lett., 30(3), 1110, doi:10.1029/2002GL016406, 2003.

Sissala, J. F., R. R. Sabatini, and H. J. Ackerman, Nimbus satellite data for polar ice survey, Polar Rec., 16, 367-377, 1972.

Stammerjohn, S. E., and R. C. Smith, Opposing southern ocean climate patterns as revealed by trends in regional sea ice coverage, Climate Change, 37, 617-639, 1997.

Streten, N. A., Satellite observations of the summer decay of the Antarctic sea-ice, Arch. Met. Biokl., Ser. A, 22, 119-134, 1973.

Thompson, D. W., and J. M. Wallace, Annular modes in the extratropical circulation Part I: Month-to-month variability, J. Climate, 13, 1000-1016, 2000. 
Thompson, D. W., and S. Solomon, Interpretation of recent southern hemisphere climate change, Science, 296, 895-899, 2002.

Vinnikov, K. Y., A. Robock, D. J. Cavalieri, and C. L. Parkinson, Analysis of seasonal cycles in climatic trends with application to satellite observations of sea ice extent, Geophys. Res. Lett., 29, 10.1029/2001GL014481 (2002).

Walsh, J., and C. M. Johnson, Interannual atmospheric variability and associated fluctuations in Arctic sea ice extent, J. Geophys. Res., 84, 6915-6928, 1979.

Zwally, H. J., J. C. Comiso, C. L. Parkinson, W. J. Campbell, F. D. Carsey, and P. Gloersen, Antarctic Sea Ice, 1973-1976: Satellite Passive-Microwave Observations, NASA, SP-459, Washington, DC, 1983a.

Zwally, H. J., C. L. Parkinson, and J. C. Comiso, Variability of Antarctic sea ice and changes in carbon dioxide, Science, 220, 1005, 1983b.

Zwally, H. J., J. C. Comiso, C. L. Parkinson, D. J. Cavalieri, and P. Gloersen, Variability of Antarctic sea ice 1979-1998, J. Geophys. Res., 107, 10.1029/2000JC000733 (2002). 

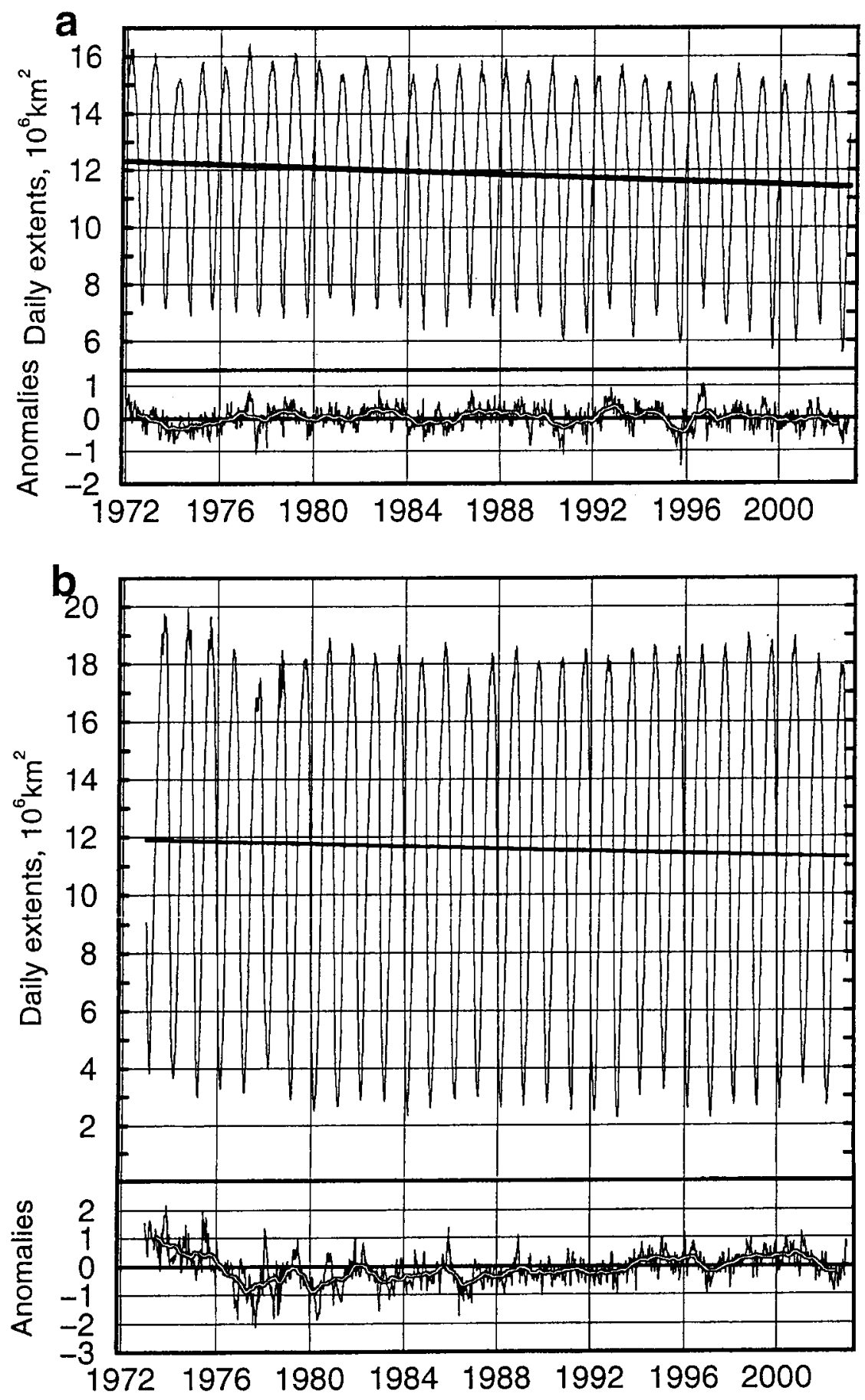

Figure 1. Matched sea ice extents from 1972/3 through 2002 and their anomalies are shown for (a) the Northern Hemisphere and (b) the Southern Hemisphere. Linear trend lines are indicated for each hemisphere, and a 365-day running mean of the anomalies is included on the anomaly plots. 
Table 1 Monthly and annual multiyear averages $a\left[10^{6} \mathrm{~km}^{2}\right]$, trend estimates $b$ $\left[10^{6} \mathrm{~km}^{2} / 10 \mathrm{yr}\right]$ and their Root Mean Square errors $\sigma_{b}\left[10^{6} \mathrm{~km}^{2} / 10 \mathrm{yr}\right]$ for both the full 30 (31)year period 1973(72)-2002 and for just the 24-year period (1979-2002).

\begin{tabular}{|c|c|c|c|c|c|c|c|c|c|c|c|c|c|}
\hline & Jan & Feb & Mar & Apr & May & Jun & Jul & Aug & Sep & Oct & Nov & Dec & Ann. \\
\hline \multicolumn{14}{|c|}{ Arctic } \\
\hline $\begin{array}{l}a_{1972-2002} \\
b_{1972-2002} \\
\sigma_{01972-2002}\end{array}$ & $\begin{array}{l}14.46 \\
-.24 \\
+.05\end{array}$ & $\begin{array}{l}15.26 \\
-.20 \\
+.05\end{array}$ & $\begin{array}{l}15.40 \\
-.27 \\
+.05\end{array}$ & $\begin{array}{l}14.77 \\
-.36 \\
+.06\end{array}$ & $\begin{array}{l}13.51 \\
-.36 \\
+.05\end{array}$ & $\begin{array}{l}12.02 \\
-.31 \\
+.04\end{array}$ & $\begin{array}{l}9.81 \\
-.35 \\
+.07\end{array}$ & $\begin{array}{l}7.58 \\
-.29 \\
+.07\end{array}$ & $\begin{array}{l}6.95 \\
-.38 \\
+.08\end{array}$ & $\begin{array}{l}8.84 \\
-.32 \\
+.07\end{array}$ & $\begin{array}{l}11.00 \\
-.25 \\
+.06\end{array}$ & $\begin{array}{l}13.03 \\
-.26 \\
+.05\end{array}$ & $\begin{array}{l}11.87 \\
-.30 \\
+.03\end{array}$ \\
\hline$b / a[\%]$ & -1.7 & -1.3 & -1.8 & -2.4 & -2.7 & -2.6 & -3.5 & -3.9 & -5.4 & -3.7 & -2.3 & -2.0 & -2.5 \\
\hline $\begin{array}{l}a_{1979-2002} \\
b_{1979-2002} \\
\sigma_{b 1979-2002}\end{array}$ & $\begin{array}{l}14.40 \\
-.32 \\
+.06\end{array}$ & $\begin{array}{l}15.20 \\
-.24 \\
+.07\end{array}$ & $\begin{array}{l}15.30 \\
-.29 \\
+.06\end{array}$ & $\begin{array}{l}14.62 \\
-.32 \\
+.08\end{array}$ & $\begin{array}{l}13.35 \\
-.25 \\
+.08\end{array}$ & $\begin{array}{l}11.93 \\
-.38 \\
+.05\end{array}$ & $\begin{array}{l}9.73 \\
-.47 \\
+.09\end{array}$ & $\begin{array}{l}7.52 \\
-.41 \\
+.11\end{array}$ & $\begin{array}{l}6.85 \\
-.48 \\
+.13\end{array}$ & $\begin{array}{l}8.73 \\
-.36 \\
+.11\end{array}$ & $\begin{array}{c}10.94 \\
-.36 \\
+.08\end{array}$ & $\begin{array}{c}12.97 \\
-.36 \\
\pm .07\end{array}$ & $\begin{array}{l}11.78 \\
-.36 \\
+.05\end{array}$ \\
\hline$b / a[\%]$ & -2.2 & -1.6 & -1.9 & -2.2 & -1.9 & -3.2 & -4.9 & -5.4 & -7.0 & -4.1 & -3.2 & -2.8 & .3 .0 \\
\hline \multicolumn{14}{|c|}{ Antarctic } \\
\hline $\begin{array}{l}a_{1973.2002} \\
b_{1973-2002} \\
\sigma_{\mathrm{b} 1973.2002}\end{array}$ & $\begin{array}{l}5.08 \\
-.36 \\
+.11\end{array}$ & $\begin{array}{l}3.14 \\
-.24 \\
+.08\end{array}$ & $\begin{array}{l}4.03 \\
-.13 \\
+.10\end{array}$ & $\begin{array}{l}6.75 \\
-.06 \\
+.13\end{array}$ & $\begin{array}{l}10.06 \\
-.06 \\
+.13\end{array}$ & $\begin{array}{l}13.23 \\
-.23 \\
+.14\end{array}$ & $\begin{array}{l}15.81 \\
-.18 \\
+.11\end{array}$ & $\begin{array}{l}17.59 \\
-.19 \\
+.10\end{array}$ & $\begin{array}{l}18.27 \\
-.06 \\
+.11\end{array}$ & $\begin{array}{l}17.87 \\
-.07 \\
+.10\end{array}$ & $\begin{array}{l}15.68 \\
-.12 \\
+.11\end{array}$ & $\begin{array}{l}10.21 \\
-.05 \\
+.13\end{array}$ & $\begin{array}{l}11.52 \\
-.15 \\
+.08\end{array}$ \\
\hline$b / a[\%]$ & -7.1 & -7.7 & -3.2 & -0.9 & -0.6 & -1.7 & -1.1 & -1.1 & -0.3 & -0.4 & -0.8 & -0.5 & -1.2 \\
\hline $\begin{array}{l}a_{1979-2002} \\
b_{1979-2002} \\
\sigma_{\mathrm{b} 1979.2002}\end{array}$ & $\begin{array}{l}4.86 \\
.00 \\
+.13\end{array}$ & $\begin{array}{l}2.98 \\
.04 \\
+.08\end{array}$ & $\begin{array}{l}3.90 \\
.19 \\
\pm .10\end{array}$ & $\begin{array}{l}6.67 \\
.21 \\
\pm .15\end{array}$ & $\begin{array}{l}9.96 \\
.28 \\
+.15\end{array}$ & $\begin{array}{l}13.09 \\
.08 \\
+.14\end{array}$ & $\begin{array}{l}15.71 \\
.01 \\
\pm .09\end{array}$ & $\begin{array}{l}17.48 \\
0.03 \\
+.08\end{array}$ & $\begin{array}{l}18.23 \\
0.04 \\
+0.09\end{array}$ & $\begin{array}{l}17.83 \\
.05 \\
+.09\end{array}$ & $\begin{array}{l}15.64 \\
-.04 \\
+.09\end{array}$ & $\begin{array}{l}10.15 \\
.12 \\
\pm .16\end{array}$ & $\begin{array}{l}11.42 \\
.09 \\
+.06\end{array}$ \\
\hline$b / a[\%]$ & 0.1 & 1.3 & 5.0 & 3.2 & 2.8 & 0.6 & 0.8 & 0.2 & 0.2 & 0.3 & -0.2 & 1.2 & 0.8 \\
\hline
\end{tabular}




\section{Popular Summary}

A 30-year record of sea ice extents derived from satellite radiometer observations reveals significant changes in the polar sea ice covers. Arctic sea ice extents decreased by $0.30 \pm 0.03 \times 10^{6} \mathrm{~km}^{2}$ per decade from 1972 through 2002 , but decreased by $0.36 \pm 0.05 \times 10^{6} \mathrm{~km}^{2}$ per decade from 1979 through 2002, indicating an acceleration of $20 \%$ in the rate of decrease. The long-term decrease in the Arctic sea ice cover appears to be related to long-term temperature trends and to changes in large-scale atmospheric circulation. In contrast to the Arctic, the Antarctic sea ice extent decreased dramatically over the period 1973-1977, then gradually increased, with an overall 30 -year trend of $-0.15 \pm 0.08 \times 10^{6} \mathrm{~km}^{2} / 10 \mathrm{yr}$. The trend reversal is attributed to a large positive anomaly in Antarctic sea ice extent observed in the early 1970 's. For the period since the 1970's, long term atmospheric variations have been identified including appreciable changes in southern hemisphere tropospheric circulation at middle and high latitudes. These changes are also evident in the trend of large-scale southern hemisphere atmospheric indices over the last few decades, with the transition from mostly negative to mostly positive indices occurring during the 1970s. The more positive indices are associated with stronger westerlies and cooler temperatures over much of Antarctica. Exactly how this trend is related, if at all, to the increase in sea ice extent since the 1970's remains to be determined. 


\section{Significant Findings with Relation to EOS Science Plan}

The significant findings of this work include the identification of an acceleration of $20 \%$ in the rate of decrease $\left(0.36 \pm 0.05 \times 10^{6} \mathrm{~km}^{2}\right.$ per decade $)$ of the Arctic ice cover from 1979 through 2002 relative to the rate $\left(0.30 \pm 0.03 \times 10^{6} \mathrm{~km}^{2}\right.$ per decade) over the entire 30-year period 1972-2002. This overall decrease in Arctic sea ice extent is statistically significant and may have resulted in part from greenhouse warming as indicated by model simulations using increased $\mathrm{CO}_{2}$ and aerosols. In contrast to the Arctic, the Antarctic sea ice extent decreased dramatically over the period 1973-1977, then gradually increased, with an overall 30-year trend of $-0.15 \pm$ $0.08 \times 10^{6} \mathrm{~km}^{2} / 10 \mathrm{yr}$. This trend reversal is attributed to a large positive anomaly in Antarctic sea ice extent observed in the early 1970's. Since the 1970's long term atmospheric variations have been identified including appreciable changes in southem hemisphere tropospheric circulation at middle and high latitudes. These changes are also evident in the trend toward more positive southern hemisphere annular mode indices over the last few decades, with the transition from mostly negative to mostly positive indices occurring during the 1970s. The more positive indices are associated with stronger westerlies and cooler temperatures over much of Antarctica. Exactly how this trend is related, if at all, to the increase in sea ice extent since the 1970's remains to be determined.

The results of this work address the Earth Science Enterprise research strategy science question: "How is the global Earth system changing?" Understanding present variability will reduce uncertainty in future predictions of how long term atmospheric variations affect changes in the polar sea ice covers. 